COLABORACIÓN ESPECIAL

\title{
VIGILANCIA MICROBIOLÓGICA DEL SARAMPIÓN Y LA RUBÉOLA EN ESPAÑA. RED DE LABORATORIOS
}

\author{
Juan Emilio Echevarría (1,2), Aurora Fernández García (1,2) y Fernando de Ory (1,2).
}

(1) Laboratorio Nacional de Referencia de Sarampión y Rubéola. Centro Nacional de Microbiología (CNM). Instituto de Salud Carlos III (ISCIII).

(2) Programa de Prevención, Vigilancia y control de las Enfermedades Transmisibles (PREVICET) del Consorcio de Investigación Biomédica de Epidemiología y Salud Pública (CIBERESP).

\section{RESUMEN}

El laboratorio es un elemento imprescindible en la vigilancia del sarampión y la rubéola, ya que los casos han de ser adecuadamente confirmados para poder estimar la incidencia de forma precisa, las cepas han de ser caracterizadas genéticamente para conocer el patrón de circulación de los virus y estudiar de forma completa los brotes y las cadenas de transmisión y la susceptibilidad de la población debe de ser determinada mediante encuestas de seroprevalencia. El diagnóstico de laboratorio de las infecciones agudas por estos agentes se basa en la detección de la respuesta inmune específica de clase IgM, que debe de complementarse con la detección del genoma del virus en exudado faríngeo $\mathrm{y} / \mathrm{u}$ orina para poder alcanzar un rendimiento diagnóstico óptimo, especialmente si la recogida de las muestras es muy temprana. El genotipado de la cepa se realiza por secuenciación genómica de acuerdo a protocolos de referencia de la OMS. La vigilancia de laboratorio de sarampión y rubéola en España se estructura en forma de red, con laboratorios autonómicos de capacidades diferentes y un Laboratorio Nacional de Referencia (LNR), que es el Centro Nacional de Microbiología, que garantiza la disponibilidad de las técnicas en todo el territorio nacional, vela por la calidad de los resultados y representa a la Red Nacional en la Red Europea de laboratorios. El LNR está actualmente implantando nuevas herramientas de caracterización molecular basadas en regiones hipervariables del genoma para la caracterización de las cepas a nivel subgenotípico y su aplicación a la vigilancia.

Palabras clave: Sarampión. Rubéola. Diagnóstico. Epidemiología molecular. Vigilancia en salud pública.

\section{ABSTRACT \\ Microbiological Surveillance of Measles and Rubella in Spain. Laboratory Network}

The Laboratory is a fundamental component on the surveillance of measles and rubella. Cases need to be properly confirmed to ensure an accurate estimation of the incidence. Strains should be genetically characterized to know the transmission pattern of these viruses and frequently, outbreaks and transmission chains can be totally discriminated only after that. Finally, the susceptibility of the population is estimated on the basis of seroprevalence surveys. Detection of specific IgM response is the base of the laboratory diagnosis of these diseases. It should be completed with genomic detection by RT-PCR to reach an optimal efficiency, especially when sampling is performed early in the course of the disease. Genotyping is performed by genomic sequencing according to reference protocols of the WHO. Laboratory surveillance of measles and rubella in Spain is organized as a net of regional laboratories with different capabilities. The National Center of Microbiology as National Reference Laboratory (NRL), supports regional laboratories ensuring the availability of all required techniques in the whole country and watching for the quality of the results. The NRL is currently working in the implementation of new molecular techniques based on the analysis of genomic hypervariable regions for the strain characterization at sub-genotypic levels and use them in the surveillance.

Key words: Measles. Rubella. Diagnosis. Molecular epidemiology. Public Health Surveillance

\author{
Correspondencia \\ Juan Emilio Echevarría \\ Laboratorio Nacional de Referencia de Sarampión y Rubéola \\ Centro Nacional de Microbiología (CNM) \\ Instituto de Salud Carlos III \\ Carretera de Majadahonda, $\mathrm{s} / \mathrm{n}$ \\ jeechevarria@isciii.es
}

DOI: 


\section{PAPEL DEL LABORATORIO \\ EN EL SISTEMA DE VIGILANCIA \\ DEL SARAMPIÓN Y LA RUBÉOLA}

\section{Estimación de la incidencia}

La piedra angular de la vigilancia epidemiológica de una enfermedad es la estimación de su incidencia y el seguimiento de su evolución y de los factores que la determinan. Cuando los rasgos clínico-epidemiológicos de una enfermedad son muy característicos, es fácil estimar el número de casos siguiendo criterios clínicos. Además del virus del sarampión y el virus de la rubéola hay otros agentes infecciosos que producen cuadros exantemáticos similares. El sarampión produce un exantema que, además de tener algunos signos clínicos característicos, cursa con síntomas especialmente severos en comparación con los de otros agentes etiológicos. La rubéola, sin embargo, cursa habitualmente de forma leve o subclínica y sus síntomas son muy parecidos a los producidos por otros agentes, como el parvovirus B19 o los enterovirus. No debemos olvidar que la razón de vacunar a toda la población de rubéola es evitar la rubéola congénita. Por otra parte, en poblaciones no inmunizadas, ambas enfermedades se presentan en forma de grandes epidemias o brotes cíclicos, esencialmente durante la infancia, que son fácilmente detectables clínicamente, de forma que el dato de la incidencia estimada de casos declarados exclusivamente en base a la clínica refleja adecuadamente la realidad, ya que el error introducido a través del diagnóstico erróneo de algunos casos no introduce una distorsión significativa. Por otra parte, no se dispone de tratamiento específico para ninguna de las dos enfermedades, por lo que un diagnóstico de certeza basado en ensayos de laboratorio no es necesario para el manejo del enfermo, a excepción de las complicaciones graves o la infección por virus de la rubéola en la mujer embarazada. Por consiguiente, durante la era prevacunal, el papel del laboratorio en la vigilancia del sarampión y la rubéola no era excesivamente relevante y se reducía a ca- racterizar los brotes o epidemias mediante la confirmación de algunos casos y al diagnóstico de las complicaciones.

El efecto de la consecución de altas coberturas vacunales en la población tiene como consecuencia la drástica disminución de la incidencia, una pérdida de los patrones epidémicos cíclicos de circulación, un desplazamiento progresivo de las curvas etarias hacia cohortes de población de más edad y un aumento paulatino de los casos clínicos compatibles que son causados por otros agentes, de forma que en un escenario teórico de erradicación alcanzarían la totalidad. Por esta razón, en la misma medida que aumentan las coberturas vacunales, lo hace el error en el cálculo de la incidencia basada en síntomas clínicos. Por tanto, la necesidad del laboratorio aumenta progresivamente. Cuando se alcanzan estadíos avanzados de control, en los que la incidencia es ya tan baja que se plantea la eliminación de las enfermedades, es imprescindible y logísticamente posible la confirmación o el descarte por el laboratorio de todos los casos sospechosos. Hemos de pensar que, si bien podría ser posible llegar algún día a erradicar estas enfermedades, nunca lo serán sus síntomas clínicos.

Establecimiento de patrones de circulación y estudio de brotes y cadenas de transmisión

Como ya hemos comentado, la caída de la incidencia a través de la consecución de altas coberturas vacunales se traduce en un desplazamiento de la edad de adquisición de la enfermedad hacia cohortes paulatinamente mayores. Asimismo, se pierde la estacionalidad típica y la mayoría de los casos son esporádicos o agrupados en pequeños brotes autolimitados. El virus deja de circular de forma autóctona para presentarse en forma de importaciones, produciéndose un cambio en los patrones de su circulación, que hace fundamental la caracterización de las nuevas formas de presentación, tanto para el manejo de los brotes, el establecimiento de estrategias de control y la evaluación del grado de progreso hacia la eliminación. De acuerdo al criterio de 
la Organización Mundial de la Salud (OMS), la distribución espacio-temporal de genotipos y variantes de los virus constituye una herramienta fundamental para estos fines. Así, el dominio de un mismo genotipo durante largos períodos que se observa cuando hay circulación autóctona del virus debería dejar paso a una situación de mayor variedad de genotipos, que irían cambiando con el tiempo en función de cómo cambie la fuente principal de importación, en general algún país del entorno geográfico, político o cultural, en el que se esté produciendo un gran brote epidémico. En este sentido, como veremos más adelante, la disponibilidad creciente de secuencias genómicas permite conocer cada vez con mayor detalle las fuentes de importación y explicar los patrones de circulación observados. Por otra parte, en un estadio próximo a la eliminación en el que la tasa de sujetos susceptibles es extremadamente baja, deberíamos esperar cadenas de transmisión muy cortas que, sin embargo, podrían coexistir si se producen importaciones coincidentes en el tiempo y en el espacio, dando la falsa sensación de una eficiencia de transmisión del virus mayor que la real. El estudio detallado de genotipos y variantes puede permitir discriminar dichas cadenas coincidentes, dando una idea más real de la capacidad del virus de transmitirse entre la población y, por tanto, del estadio de progreso hacia la eliminación.

Evaluación de la susceptibilidad de la población

Existen dos aproximaciones para evaluar el estado inmunitario frente a las infecciones inmunoprevenibles. En primer lugar, mediante la revisión de registros de vacunación, aspecto que es objeto de revisión en otro artículo de este número, o alternativamente mediante la realización de estudios de seroprevalencia. Para su realización se requiere una muestra que represente de forma fiable a la población (por edad, sexo, factores demográficos y socioeconómicos), siendo especialmente recomendables muestras de población seleccionadas específicamente para estos estudios. Sin embargo, realizar una investiga- ción de seroprevalencia basada en el estudio de una muestra tomada ad hoc resulta una aproximación de elevado coste por lo que, en algunas ocasiones, se emplean materiales residuales de laboratorios de análisis o muestras de donantes de sangre. Por otra parte, se requieren técnicas que detecten anticuerpos que indiquen protección o, en su defecto, técnicas que detecten Inmunoglobulina $\mathrm{G}(\mathrm{IgG})$, en general técnicas de ELISA, que muestren buena comparabilidad con las que indican protección.

En España se han realizado diversas encuestas que implican a los virus del sarampión y rubéola sobre muestras representativas de la población general, tanto a nivel nacional $(1996)^{1}$ como a nivel de diferentes comunidades autónomas: Madrid (1993, 1999 y 2008-09)2 , Andalucía (1996) ${ }^{3}$, Asturias (2002 y 2009)(Dirección General de Salud Pública del Principado de Asturias, datos sin publicar), País Vasco ${ }^{4}$ o en donantes de sangre, $(\text { Galicia, 2007) })^{5}$. Todas estas encuestas se realizaron con la misma metodología (ELISA) del mismo fabricante, lo que hace posible la comparación de los resultados (tablas 1 y 2). Estos estudios identificaron algunos fallos en la inmunidad de la población, permitiendo aplicar las medidas correctoras adecuadas. A modo de ejemplo, se observó una importante disminución en la seroprevalencia en niños de 6 a 9 años, en la Comunidad de Madrid en 1993 (frente a rubéola y sarampión) y en la encuesta nacional en 1996 (frente a sarampión). El adelanto de la administración de la segunda dosis de la vacuna triple vírica permitió subsanar este defecto.

Un aspecto importante a considerar es el nivel de protección en los individuos seropositivos, valorado como título de anticuerpos. Cuando se calculan las medias de los títulos por grupos de edad se observa que, tanto para sarampión como para rubéola, los títulos de anticuerpos siempre han sido más altos en los individuos nacidos antes de la generalización del uso de las vacunas, lo que sugiere dos posibilidades. Una que la inmunidad inducida 


\begin{tabular}{|l|c|}
\hline \multicolumn{10}{|c|}{ Tabla 1 } \\
Seroprevalencia frente a virus sarampión en encuestas seroepidemiológicas \\
representativas de la población \\
\hline
\end{tabular}

\begin{tabular}{|c|c|c|c|c|c|c|c|c|c|}
\hline \multicolumn{10}{|c|}{$\begin{array}{c}\text { Tabla } 2 \\
\begin{array}{c}\text { Seroprevalencia frente a virus rubéola en encuestas seroepidemiológicas } \\
\text { representativas de la población }\end{array}\end{array}$} \\
\hline & España & Andalucía & \multicolumn{3}{|c|}{ Comunidad de Madrid } & \multicolumn{2}{|c|}{ Asturias } & \multirow{2}{*}{$\begin{array}{c}\text { Galicia } \\
2008\end{array}$} & \multirow{2}{*}{$\begin{array}{c}\text { País } \\
\text { Vasco } \\
2011 \\
\end{array}$} \\
\hline Edad & 1996 & 1996 & 1993 & 1999 & 2008 & 2002 & 2009 & & \\
\hline $2-5$ & 98 & 98,1 & 98 & 95,5 & 98,7 & 99,1 & 100 & & 95,4 \\
\hline $6-9$ & 95 & 96,6 & 90,6 & 95,2 & 98,5 & 100 & 100 & & 93,8 \\
\hline $10-14$ & 95,7 & 95,1 & 91,8 & 98,8 & 98,9 & 100 & 99,4 & & 98,9 \\
\hline $15-19$ & 93,8 & 90,9 & 94,5 & 95,9 & 98,1 & 95,7 & 97 & \multirow{2}{*}{$97,4^{3}$} & 98,9 \\
\hline $20-24$ & 96,4 & \multirow{2}{*}{94,2} & \multirow{2}{*}{98,6} & \multirow{2}{*}{98,7} & \multirow{2}{*}{95,8} & \multirow{2}{*}{98,3} & \multirow{2}{*}{97,5} & & 98,3 \\
\hline $25-29$ & 96,7 & & & & & & & 94,4 & 97,4 \\
\hline $30-39$ & 96,8 & 96,1 & 98,5 & 99,1 & 96,9 & 99,4 & 100 & 96,7 & 96,9 \\
\hline $40-64$ & & & & & $97,1^{1}$ & $99,1^{2}$ & $97,6^{2}$ & 97 & $97,7^{4}$ \\
\hline
\end{tabular}

por la vacuna pueda ser menor que la inducida por la infección natural. Y dos, que la circulación de los virus en la era prevacunal o durante los primeros años de la vacuna, antes de la generalización de su uso, favoreciera sucesivas exposiciones al virus, reforzando la inmunidad.

El principal objetivo de las encuestas de seroprevalencia es identificar posibles grupos de población desprotegida. En este sentido, hay que considerar los cambios poblacionales ocurridos en los últimos años, que supusieron un incremento de emigración a nuestro país procedente de países con calendarios vacunales diferentes al español, que no incluían las vacunas de rubéola y/o sarampión. En algunos brotes de rubéola ocurridos en los últimos años fueron afectados individuos procedentes de Latinoamérica. Alguna de las encuestas realizadas en España ha tenido en cuenta este factor, observándose una menor protección en población inmigrante que, en el caso de la rubéola, podría tener un impacto en nuevos casos de infección congénita.

\section{MÉTODOS DE LABORATORIO PARA EL DIAGNÓSTICO DE SARAMPIÓN Y RUBÉOLA}

En la infección por estos virus, después del periodo de incubación (de 15 a 17 días en el caso de rubéola y de 7 a 18 en el del sarampión) se produce la sintomatología clínica. El sarampión comienza con una fase prodrómica (fiebre, conjuntivitis, coriza, tos y manchas 
de Koplik), de tres días de duración, tras la que aparece un exantema máculo-papular, que comienza en la cara, generalizándose a continuación. Por otra parte, la rubéola se caracteriza por la presencia de un exantema máculo-papular. En niños suele existir poca sintomatología (o ser asintomática) y en adultos, por el contrario, pueden sufrir un pródromo similar al del sarampión, seguido por linfadenopatía.

La OMS propone una definición de caso clínico para sarampión, recogida en el Plan Nacional de Eliminación, que incluye fiebre superior a $38^{\circ} \mathrm{C}$ y exantema máculo-papular, acompañado de al menos uno de estos tres síntomas: tos, rinitis/coriza y conjuntivitis ${ }^{6}$. En el caso de rubéola el caso clínico se define como persona en la que aparece de manera súbita un exantema máculo-papular generalizado y al menos uno de los cinco criterios siguientes: adenopatía cervical, suboccipital, retroauricular, artralgias o artritis ${ }^{6}$.

El virus puede ser identificado en la muestra clínica adecuada en los días alrededor del comienzo de los síntomas. Unos pocos días después comienza a producirse una respuesta específica de anticuerpos que, en primer lugar son de la clase IgM (que duran 2-3 meses), seguidos por IgG, que alcanzan el pico a los 15 días y que permanecen detectables durante toda la vida. Así el diagnóstico de laboratorio de rubéola y sarampión se basa tanto en métodos directos, para identificar el agente que produce la enfermedad, como en métodos indirectos, para determinar la respuesta específica de anticuerpos.

\section{Técnicas de detección directa}

La detección de un agente infeccioso en una muestra coincidente o lo más cercana posible al lugar donde se manifiestan los síntomas, es la manera más directa de diagnosticar una infección. En el caso del sarampión y la rubéola se puede demostrar la infección a través de la presencia del virus en el torrente sanguíneo o su excreción por el tracto respiratorio o por la orina. En ambos casos, la viremia suele ser corta y su máximo suele coincidir con los síntomas prodrómicos más que con el exantema, que se produce en gran medida por deposición de inmunocomplejos $\mathrm{y}$, por tanto, se retrasa hasta que hay una respuesta inmune suficientemente potente. Por el contrario, la excreción en orofaringe y orina coincide plenamente con el exantema y es detectable aún cuando está finalizando. Por esta razón, la detección del virus en exudado faríngeo y orina es un marcador mucho más eficiente que la detección en suero o sangre.

La técnica más clásica para detectar virus del sarampión y virus de la rubéola es el aislamiento en cultivo celular. Actualmente, la OMS recomienda el uso de una línea celular Vero que ha sido modificada para expresar el receptor del virus del sarampión (VeroSlam). El aislamiento en cultivo de cualquiera de los dos virus es un proceso que suele necesitar varios días y que está muy influenciado tanto por el momento de toma de la muestra como por su adecuada conservación y transporte al laboratorio.

En la actualidad la técnica más utilizada para la detección directa es la amplificación del genoma de estos virus mediante reacción en cadena de la polimerasa con transcriptasa inversa (RT-PCR), utilizando cebadores dirigidos frente a regiones altamente conservadas y aplicada con éxito en diferentes muestras clínicas. Es una técnica más rápida, sencilla y sensible que el aislamiento en cultivo celular y permite la caracterización genotípica de la cepa por secuenciación genómica. Por esta razón, la está reemplazando como técnica de cribado, aunque el aislamiento en cultivo celular es la única técnica capaz de facilitar la caracterización fenotípica de la cepa, por lo que su disponibilidad es obligada en laboratorios de referencia. Además se ha desarrollado una RT-PCR múltiple que permite realizar de manera simultánea el diagnóstico frente a sarampión y rubéola, al tiempo que un diagnóstico diferencial con otro virus exantemático como parvovirus $\mathrm{B} 19^{7,8}$. 


\section{Técnicas serológicas}

Hay dos aproximaciones diferentes para hacer el diagnóstico serológico: la detección de IgM en muestra tomada en la fase aguda de la enfermedad y la detección de seroconversión de anticuerpos totales o de IgG específica en dos muestras separadas 1 o 2 semanas. Obviamente, la seroconversión no proporciona un diagnóstico rápido, por lo que la determinación de IgM resulta el método más adecuado para hacer el diagnóstico serológico y es la técnica de referencia que la OMS considera hasta el momento para el diagnóstico de laboratorio. Sin embargo, si la muestra está tomada muy cerca del comienzo de los síntomas y es IgM negativa se requiere el análisis de otra muestra de seguimiento.

Existen diferentes ensayos disponibles comercialmente para la determinación de anticuerpos específicos de clase IgG e IgM frente a ambos virus: ELISA, quimioluminiscencia, inmunofluorescencia indirecta. Para rubéola, además, se han desarrollado métodos de inmunocromatografía, inmunofiltración $\mathrm{o}$ inmunoblot, con buenas características en su funcionamiento tanto para diagnóstico (ensayos de $\operatorname{IgM}$ ) como para determinar inmunidad o seroconversión (ensayos de IgG). Actualmente están en desuso ensayos clásicos que detectan anticuerpos totales (inhibición de hemaglutinación, neutralización, o fijación del complemento), por ser técnicas laboriosas generalmente realizadas con procedimientos propios de los laboratorios.

A pesar de que la determinación de IgM es el método de elección para hacer el diagnóstico serológico de rubéola y sarampión, existen algunos inconvenientes en su aplicación a estos virus. En primer lugar, la presencia simultánea de IgG específica y factor reumatoide puede resultar en reactividades falsamente positivas, que se resuelven eliminando la IgG de la muestra previamente a su análisis. Por otra parte, la estimulación policlonal de linfocitos B de memoria que ocurre en algunas infecciones puede resultar en reactividad IgM frente a patógenos que han infectado al pa- ciente en el pasado. Además, se han descrito como relativamente frecuentes reactividades heterólogas positivas de IgM en infecciones por rubéola, sarampión y parvovirus B19, siendo los tres una causa importante de enfermedad exantemática, entre los que se requiere habitualmente el diagnóstico diferencial. Por último, la IgM específica puede persistir durante períodos largos de tiempo en ausencia de sintomatología clínica, como consecuencia de una infección previa. Para resolver estos problemas se han aplicado métodos confirmatorios. Por una parte, el estudio de anticuerpos frente a proteínas purificadas es de gran utilidad para confirmar la infección reciente por el virus de la rubéola: ensayos de ELISA que emplean como antígeno glicoproteínas purificadas del virus muestran mayor sensibilidad y especificidad que ensayos que emplean lisados virales. Además, también en el caso de rubéola, la ausencia de respuesta detectable frente a la glicoproteína E2 es un marcador reconocido de infección reciente, en tanto que se obtienen resultados positivos en casos de persistencia de IgM, infecciones pasadas o infecciones por otros agentes, siendo un adecuado marcador de exclusión ${ }^{9}$. Igualmente, los ensayos de avidez de IgG permiten de forma fiable confirmar la infección primaria tanto por virus de la rubéola, aspecto importante especialmente para la confirmación/exclusión de la infección durante el embarazo ${ }^{10}$ como por virus del sarampión, en el que es importante la identificación de fallo vacunal $^{11}$.

\section{Técnicas de genotipado}

Como ya se ha dicho previamente, el genotipado de los casos es una herramienta fundamental en la vigilancia del sarampión y la rubéola. Las técnicas de genotipado se basan en la amplificación mediante RT-PCR, secuenciación y posterior análisis filogenético de regiones variables del genoma de estos virus.

En el virus del sarampión una de las regiones más variables del genoma son los 450 nucleótidos (nt) que codifican el extremo car- 
boxilo de la nucleoproteína $(\mathrm{N}-450)$ y, según la OMS, esta es la mínima secuencia requerida para asignar el genotipo. Además de esta técnica, se debe utilizar al menos la secuencia de la región codificante completa del gen de la hemaglutinina $(\mathrm{H})$ para la descripción de un nuevo genotipo. Un nuevo genotipo además debe basarse en el análisis de secuencias obtenidas de múltiples casos y al menos un aislado vírico, que se utilizará como cepa de referencia. Así se han definido 24 genotipos (A, B1-B3, C1, C2, D1-D11, E, F, G1-G3, H1 y H2) correspondientes a 8 grupos filogenéticos $(\mathrm{A}-\mathrm{H})^{12}$. La OMS establece una secuencia de referencia para cada genotipo. Estas a veces divergen filogenéticamente de las secuencias contemporáneas, pero sirven para asignar el genotipo a las nuevas secuencias con una buena precisión. Así, el análisis de las 7.691 secuencias de $\mathrm{N}-450$ disponibles en las bases de datos en el año 2012 permitió confirmar que la estructura genotípica definida en 2001 con una cantidad mucho menor de secuencias se mantiene ${ }^{12}$.

En nuestro país desde la entrada en vigor del Plan Nacional de Eliminación en el 2001 hasta la actualidad se han dado casos de 12 genotipos diferentes, importados de los países con los que nuestro país mantiene relación, de los cuales tres han sido los mayoritarios: D4, D8 y B3. Más de la mitad de las secuencias españolas de las que se dispone son de genotipo D4 y alrededor de la mitad se corresponden con el período de los grandes brotes que tuvieron lugar en los años 2010-2012. En el año 2013 se produjo la sustitución de este genotipo por el D8 y sin embargo el genotipo B3 se ha introducido a lo largo de todo el período en diferentes ocasiones.
En el virus de la rubéola el genotipado se basa en una secuencia de $739 \mathrm{nt}$ (del nt 8731 al nt 9469) de la región codificante del gen $\mathrm{E} 1^{13}$. Para describir un nuevo genotipo se necesita la secuencia completa de la región del genoma que codifica las proteínas estructurales (3192 nt) de dos cepas de referencia para cada genotipo. Así se han definido 12 genotipos $(1 \mathrm{~B}, 1 \mathrm{C}, 1 \mathrm{D}, 1 \mathrm{E}, 1 \mathrm{~F}, 1 \mathrm{G}$, $1 \mathrm{H}, 1 \mathrm{I}, 1 \mathrm{~J}, 2 \mathrm{~A}, 2 \mathrm{~B}, 2 \mathrm{C})$ y uno provisional (1a), pertenecientes a 2 grupos filogenéticos (1 y 2$)^{14}$. Los genotipos más frecuentemente identificados son cuatro: $1 \mathrm{E}, 1 \mathrm{G}, 1 \mathrm{~J}$ y $2 \mathrm{~B}$.

En nuestro país se han identificado desde 1998 hasta cinco genotipos diferentes (1a, 1E, 1I, 1J, y 2B) (tabla 3), con un posible patrón de importaciones esporádicas sin circulación endémica. De estos genotipos se produjo una circulación prácticamente exclusiva del genotipo $1 \mathrm{E}$ inicialmente, con un posible origen europeo. Posteriormente se produjo un reemplazo de este genotipo por el $2 \mathrm{~B}$, de origen europeo, y un gran brote de $1 \mathrm{~J}$ en 2004-2005, probablemente de origen latinoamericano. Este genotipo no había sido detectado en Europa hasta ese momento. La infección por el genotipo 1I pareció deberse a la reactivación de una infección persistente adquirida en el pasado en una paciente inmunodeprimida (datos no publicados), puesto que era un genotipo que se consideraba inactivo en Europa desde 1994. La infección por virus vacunal RA27/3 sugiere transmisión secundaria. Dos de los casos eran personas inmunodeprimidas, lo que explica la presencia de síntomas clínicos asociados.

Tabla 3

Distribución de genotipos del virus de la rubéola en España (1998-2014)

\begin{tabular}{|l|c|c|c|c|c|c|c|c|c|c|c|}
\hline & 1998 & 2003 & 2004 & 2005 & 2006 & 2007 & 2008 & 2009 & 2012 & 2013 & 2014 \\
\hline Andalucía & & & & $1 \mathrm{~J}$ & & & $2 \mathrm{~B}$ & $1 \mathrm{E}$ & & & $2 \mathrm{~B}$ \\
\hline Aragón & & & 2B & & & & & & $2 \mathrm{~B}$ & $1 \mathrm{a}$ & \\
\hline Canarias & $1 \mathrm{E}$ & & & & & & & & & & \\
\hline Castilla-La Mancha & & & & & & & $1 \mathrm{I}$ & & & $2 \mathrm{~B}$ & \\
\hline Comunidad de Madrid & & $1 \mathrm{E}$ & $1 \mathrm{~J}$ & $1 \mathrm{~J}$ & $2 \mathrm{~B}$ & & $2 \mathrm{~B}$ & $1 \mathrm{a}$ & $2 \mathrm{~B}$ & & \\
\hline Comunidad Valenciana & & & & & & & $2 \mathrm{~B}$ & & $2 \mathrm{~B}$ & & $1 \mathrm{~J}$ \\
\hline Castilla y León & & & & & & & & & & & $1 \mathrm{a}$ \\
\hline Cataluña & & & & & & $1 \mathrm{~J}$ & & & $2 \mathrm{~B}$ & & $1 \mathrm{~J}$ \\
\hline
\end{tabular}


Rendimiento comparativo de las técnicas diagnósticas

Como se ha comentado, las aproximaciones directas e indirectas para el diagnóstico de laboratorio son complementarias, mejorándose de forma importante el diagnóstico cuando se emplean ambos tipos de metodología. Existe un par de experiencias en nuestro ámbito relativas a estos virus, la primera de ellas referida al virus del sarampión ${ }^{8}$. Cuando se analizaron 248 casos de sarampión de un brote que ocurrió en Almería en 2003, en los que se dispuso de suero, orina y exudado faríngeo, se obtuvo resultado positivo en 165 casos. De estos, $136(82,4 \%)$ fueron positivos tanto por serología como por detección directa (PCR), 27 (16,4\%) solo por PCR y 2 $(1,2 \%)$ solo por IgM. Por tanto fueron positivos por PCR 163 casos $(98,8 \%)$ y por IgM 138 casos $(83,6 \%)$. Un aspecto importante es que en 23 de los 25 casos que fueron IgM negativos las muestras tenían cinco o menos días de evolución.

En otro estudio, relativo al virus de la rubéola ${ }^{15}$ al estudiar 75 casos de un brote en Madrid en 2005, con suero, exudado faríngeo y orina, se obtuvo resultado positivo en 58 , de los que $39(67,2 \%)$ fueron positivos en ambas aproximaciones, 16 (27,6\%) solo en PCR y 3 $(5,2 \%)$ solo en IgM.

\section{RED ESPAÑOLA DE LABORATORIOS DE SARAMPIÓN Y RUBÉOLA. COMPOSICIÓN, ORGANIZACIÓN, FUNCIONAMIENTO Y ACTIVIDAD}

La vigilancia de laboratorio de sarampión y rubéola se estructura en forma de red, con laboratorios autonómicos y un Laboratorio Nacional de Referencia (LNR) que es el Centro Nacional de Microbiología.

La organización de los laboratorios es diferente en cada comunidad autónoma. Algunas han designado un único laboratorio, mientras que otras tienen varios. De la misma manera, la disponibilidad de técnicas de laboratorio es diferente en cada caso. Algunas comuni- dades autónomas cubren el panel completo, abarcando serología, detección directa y genotipado, mientras que otras sólo lo hacen parcialmente. El LNR complementa las capacidades de cada una, de forma que al final esté garantizado el panel completo de técnicas en todo el territorio del Estado.

Los laboratorios autonómicos comunican los resultados a los servicios de salud pública de su comunidad autónoma y estos a la base de datos nacional del Centro Nacional de Epidemiología (CNE), a partir de la cual se elaboran los informes anuales para la OMS.

El Centro Nacional de Microbiología como Laboratorio Nacional de Referencia de sarampión y rubéola.

En el Plan de Eliminación del Sarampión y de la Rubéola y el Control de la Rubéola Congénita, el LNR oferta metodologías para la realización del diagnóstico y control de estas enfermedades ${ }^{16}$. En concreto, desde el punto de vista de la serología, están disponibles determinaciones de $\operatorname{IgG}$ e IgM frente a ambos virus, disponiéndose de metodología para la caracterización de la avidez de IgG específica frente al virus de la rubéola, así como de marcadores diagnósticos de infección frente a otros virus para los que se puede plantear, en función de antecedentes clínicoepidemiológicos, diagnóstico diferencial con rubéola y sarampión (parvovirus B19, dengue y otros). Por otra parte, se realizan igualmente determinaciones para valorar el estado inmunitario frente a ambos virus, de interés con el fin de conocer el estado vacunal. En lo que se refiere al diagnóstico directo está a disposición un ensayo de PCR múltiple para identificación de virus rubéola, sarampión y parvovirus B19, así como metodologías de PCR para otros agentes potencialmente causantes de enfermedad exantemática (Herpes Virus Humano 6, enterovirus, adenovirus, etcétera). Las determinaciones de vigilancia de sarampión y rubéola se consideran de especial interés estratégico, por lo que se realizan en el contexto de un programa de vigilancia microbiológica, sin coste para los solicitantes. En la 
aplicación telemática de la cartera de servicios del CNM figuran los criterios de inclusión en el programa que, esencialmente, se ajustan a los procedimientos del Plan Nacional de Eliminación del Sarampión y la Rubéola en España ${ }^{16}$.

Como ya hemos indicado anteriormente, el LNR tiene como primera misión asegurar la disponibilidad de todas las técnicas necesarias para una vigilancia de calidad en todo el territorio nacional, complementando, para ello, a los laboratorios autonómicos.

En relación con la Red Nacional de Laboratorios, el LNR tiene diversas actividades conducentes a la mejora del diagnóstico y control de sarampión y rubéola. En primer lugar, actuar en la confirmación de casos que por sus características lo requieran, siendo especialmente importante la confirmación o exclusión de casos de infección primaria por virus de la rubéola en el embarazo. Es importante, por otra parte, asegurar que los resultados emitidos por laboratorios de nivel sub-nacional cumplen los mismos criterios de calidad que los emitidos por el LNR, para lo que es de gran interés el establecimiento de paneles de control de calidad que permitan valorar las características de funcionamiento de los ensayos empleados por laboratorios autonómicos. En este sentido, se realizó un control de calidad de serología que permitió, por una parte, identificar los ensayos empleados en los laboratorios autonómicos y, por otra, detectar algunas debilidades de algunos de ellos ${ }^{17}$. Como una actividad de futuro se plantea volver a realizar controles de calidad entre los laboratorios que realizan el diagnóstico de sarampión y rubéola, tanto de detección directa como de serología, especialmente entre aquellos que puedan ser reconocidos como laboratorios de referencia en las comunidades autónomas.

Finalmente, el LNR representa a la Red Nacional en el contexto de la Red Europea de Laboratorios de Sarampión y Rubéola de la OMS, para lo cual acude a reuniones internacionales de forma periódica en las que, entre otras cosas, aporta información sobre la Red Nacional.
En la actualidad el LNR tiene parcialmente acreditadas, tanto por la OMS como por ENAC (ISO 15189), las técnicas que se aplican al diagnóstico y control de rubéola y sarampión.

Nuevas herramientas de caracterización molecular al servicio de la vigilancia epidemiológica de sarampión y rubéola. Variantes, haplotipos y nuevas regiones hipervariables

La epidemiología molecular es una herramienta fundamental para la vigilancia de estas dos enfermedades. La caracterización molecular de los casos ayuda en la clasificación de los mismos como importados o autóctonos, facilita el estudio de las cadenas de transmisión y es fundamental para determinar el patrón de circulación de las cepas y evaluar el progreso hacia la eliminación. En la actualidad el genotipado es un método valioso pero insuficiente para esto. En el contexto de grandes brotes de sarampión que se están produciendo en Europa en los últimos años vemos como están producidos por un genotipo dominante, el D4 hasta el año 2012 y el D8 desde el año 2013, en los que las cepas que los producen poseen secuencias N-450 muy similares e incluso idénticas en muchos casos. Se denomina haplotipo a un conjunto de secuencias idénticas y alcanza el rango de variante de secuencia cuando ha sufrido una amplia distribución tanto temporal como geográfica. La secuencia más antigua dentro de cada haplotipo o variante es la que da le da el nombre ${ }^{12}$. A modo de ejemplo, algunas de las variantes más prevalentes en Europa para cada uno de los genotipos mayoritarios han sido: MVs/Manchester.GBR/10.09/-variant (D4-Manchester), MVs/FrankfurtMain. DEU/17.11/-variant (D8-FrankfurtMain) o MVi/Harare.ZWE/38.09-variant (B3-Harare).

Para estos estudios se utilizan métodos filogenéticos y el análisis de las secuencias disponibles en las bases de datos (MeaNS para sarampión y RubeNS para rubéola). El análisis de estas variantes de secuencia permite establecer los patrones de circulación del virus del sarampión de una forma más exhaustiva 
que el genotipado, razón por la cual se está introduciendo como herramienta para la vigilancia epidemiológica de esta enfermedad. En nuestro país el LNR y el CNE colaboran de forma estrecha para integrar los datos obtenidos mediante epidemiología molecular y los datos epidemiológicos. En el caso del virus de la rubéola la disponibilidad de secuencias en las bases de datos es menor y la utilización de esta metodología aún no está generalizada.

Recientemente se han descrito las variantes mayoritarias del virus de sarampión que circularon en Europa en los últimos años, algunas de ellas muy prevalentes ${ }^{18}$. En nuestro país circularon las mismas variantes descritas en otros países europeos: D4-Enfield (20072011), D4-Hamburgo (2008-2011), D4-Manchester (2010-2012) y sus variantes: D4-Marmande y D4-Maramures $(2011)^{19}$. En el año 2013 se produjo el reemplazo por el genotipo D8, circulando fundamentalmente las variantes D8-Villupuram y D8-FrankfurtMain ${ }^{20}$, así como la variante D8-Rostov On Don en el año 2015. En el año 2013 y 2014 también se han producido brotes en nuestro país del genotipo B3, fundamentalmente de la variante B3Harare o de haplotipos relacionados con ella (datos no publicados).

Sin embargo el análisis filogenético de $\mathrm{N}-450$ no es suficiente para poder determinar las cadenas de transmisión, por ejemplo dentro de un brote o para determinar el origen de un caso en variantes ampliamente distribuidas mundialmente y poder clasificarlo como importado o no. Por esta razón se ha desarrollado una RT-PCR destinada a amplificar la región hipervariable intergénica sita entre los genes que codifican las proteínas M y F (sin publicar). Esta región aporta mayor información filogenética y permite distinguir cepas diferentes entre secuencias idénticas de $\mathrm{N}-450^{20}$.

\section{AGRADECIMIENTOS}

A Ana Fernández Verdugo, de la Consejería de Sanidad, Dirección General de Salud Pública del Principado de Asturias, por la comunicación de los datos no publicados de seroprevalencia frente a sarampión y rubéola.

El desarrollo de nuevas herramientas de caracterización molecular para la vigilancia de sarampión y rubéola ha sido financiado por un proyecto de investigación de la Acción Estratégica en Salud del ISCIII (PI12/02006). Aurora Fernández García está financiada por el CIBERESP.

A los técnicos de laboratorio Pilar Balfagón, Ana Castellanos, Jesús María de la Fuente, Concepción Hoyas y Teodora Minguito por su labor diaria en el diagnóstico de las infecciones por estos virus.

\section{BIBLIOGRAFÍA}

1. Amela C, Pachón I, de Ory F. Evaluation of the measles, mumps and rubella immunisation programme in Spain by using a sero-epidemiological survey. Eur J Epidemiol. 2003; 18: 71-79.

2. García Comas L, Ordobás M, Sanz JC, Ramos B, García J, Cevallos C, Verdejo J, Barranco D, Astray J, Echevarría JM, Ortiz M, del Amo J, Moreno S. Seroprevalence of measles and rubella virus antibodies in the population of the Community of Madrid, 2008-2009. J Infect Public Health. 2015; 8: 432-440.

3. Gallardo García V, Camino Durán F, García León J, Escalera Urquiaga MA, Sánchez Cruz JJ, Cabrera León A, Álvarez Gutiérrez JM. Sevilla: Junta de Andalucía; 1999.

4. Arteagoitia Axpe JM, García Calabuig MA, Sáez López I, Muniozguren Agirre N, González Sancristobal I, Dorronsoro Iraeta M, et al. I Encuesta de Seroprevalencia de la Comunidad Autónoma del País Vasco. Vitoria: Servicio Central de Publicaciones del Gobierno Vasco;2011.

5. Servizo de Epidemioloxía, Dirección Xeral de Saúde Pública. Enquisa Galega de Seroprevalencia 2007. Bol Epidemiol Galicia. 2008; XXI: 1-4.

6. Centro Nacional de Epidemiología. Instituto de Salud Carlos III. Red Nacional de Vigilancia Epidemiológica. Protocolos de enfermedades de declaración obligatoria. Madrid: CNE; 2013. Disponible en: http://www.isciii.es/ ISCIII/es/contenidos/fd-servicios-cientifico-tecnicos/fdvigilancias-alertas/fd-procedimientos/PROTOCOLOS RENAVE-ciber.pdf

7. Mosquera MM, de Ory F, Moreno M, Echevarría JE. Simultaneous detection of measles virus, rubella virus and parvovirus B19 by using multiplex PCR. J Clin Microbiol. 2002; 40: 111-116. 
8. Mosquera MM, de Ory F, Gallardo V, Cuenca L, Morales M, Sánchez Yebra W, Cabezas T, Hernández JM, Echevarría JE. Evaluation of Diagnostic Markers for Measles Infection in the context of an outbreak in Spain. J Clin Microbiol. 2005; 43: 5117-5121.

9. Wandinger KP, Saschenbrecker S, Steinhagen K, Scheper T, Meyer W, Bartelt U, Enders G. Diagnosis of recent primary rubella virus infections: Significance of glycoprotein-based IgM serology, IgG avidity and immunoblot analysis. J Virol Methods. 2011; 174: 85-93.

10. De Ory F, Casas I, Domingo CJ, Echevarría JM. Application of fluoroimmunoassay to the identification of low avidity specific IgG against pathogenic human viruses and Toxoplasma gondii. Clin Diagn Virol. 1995; 3: $323-332$

11. Mercader S, Garcia P, Bellini WJ. Measles Virus IgG Avidity Assay for Use in Classification of Measles Vaccine Failure in Measles Elimination Settings. Clin Vaccine Immunol. 2012; 19: 1810-1817.

12. WHO. Measles virus nomenclature update: 2012. Wkly Wpidemiol Rec. 2012; 87:73-81.

13. Martínez-Torres AO., Mosquera MM, Sanz JC, Ramos B, Echevarría JE. Phylogenetic analysis of rubella virus strains from an outbreak in Madrid, Spain, from 2004 to 2005. J Clin Microbiol. 2009; 47:158-163.

14. WHO. Rubella virus nomenclature update: 2013. Wkly Epidemiol Rec. 2013; 88: 337-348.

15. Mosquera Gutiérrez MM, Sanz Moreno JC, Echevarría Mayo JE, Herranz Redondo N, Fernández Díaz M, de Ory Manchón F. Estudio del rendimiento diagnóstico de la detección de IgM específica y de la amplificación genómica de rubéola. Enferm Infecc Microbiol Clin. 2006; 24: 251-253.

16. Boletín Oficial del Estado. Resolución de 12 de junio de 2015, del Instituto de Salud Carlos III, por la que se establecen los precios públicos por la prestación de servicios y actividades del organismo. BOE núm 154 de 29-6-2015.

17. de Ory F, Sanz JC, Echevarría JE, Mosquera M, Guisasola ME y Red de Laboratorios Autonómicos para el Plan de Eliminación del Sarampión. Comparación de los procedimientos serológicos de los laboratorios del Plan para la Eliminación del Sarampión en el diagnóstico de exantemas víricos. Enferm Infecc Microbiol Clin. 2004; 22:319-322.

18 Santibanez S, Hübschen JM, Muller CP, Freymuth F, Mosquera MM, Mamou MB, Mulders MN, Brown KE, Myers R, Mankertz A. Long-term transmission of measles virus in Central and continental Western Europe. Virus Genes. 2015; 50:2-11.
19 Gómez-Vecino A, Echevarria JE, Mosquera MM, Hoyas C, Castellanos A, de Ory F, Fernández-García A. Molecular epidemiology of measles virus genotype D4 in Spain. 12th National Congress of the Italian Society for Virology. Orvieto; 2014.

20. Fernández-García A, Masa-Calles J, Mosquera MM, López-Perea N, Gómez-Vecino A, Castellanos A, Hoyas C, Costa J, Isanta R, de Ory F, Echevarria JE. Epidemiología molecular de las cepas del virus del sarampión del genotipo D8 en España (2001-2014). XIX Congreso de la Sociedad Española de Enfermedades Infecciosas y Microbiología Clínica (SEIMC). Enferm Infecc Microbiol Clin. 2015; 33(Espec Cong 1) :19 